\title{
Avaliação da eficiência do plano de manejo para zona de amortecimento
}

\author{
Evaluation of the efficiency of the management plan for the zone of damping \\ Evaluación de la eficiencia del plan de gestión de la zona de búfer
}

Recebido: 14/10/2021 | Revisado: 20/10/2021 | Aceito: 25/10/2021 | Publicado: 28/10/2021

Natielly Cristine Gomes de Medeiros

ORCID: https://orcid.org/0000-0002-3996-5702

Universidade Federal de Campina Grande, Brasil

E-mail: natiellymedeiros7@gmail.com

João Batista Alves

ORCID: https://orcid.org/0000-0002-1548-7996

Universidade Federal de Campina Grande, Brasil

E-mail: alvesjb@uol.com.br

Francisco das Chagas Vieira Sales

ORCID: https://orcid.org/0000-0002-5923-6312

Universidade Federal de Campina Grande, Brasil

E-mail: franciscoef@yahoo.com.br

Mikaella Meira Monteiro

ORCID: https://orcid.org/0000-0002-2741-3273

Universidade Federal de Campina Grande, Brasil

E-mail: mikaellaflorestal@gmail.com

Jéssica Gomes Fontes Nery

ORCID: https://orcid.org/0000-0002-8101-8047

Universidade Federal de Campina Grande, Brasil

E-mail: jessicagfonts@gmail.com

Kyegla Beatriz da Silva Martins

ORCID: https://orcid.org/0000-0002-3261-1389

Universidade Federal de Campina Grande, Brasil

E-mail: kyeglabeatriz23@gmail.com

Sávio Maciel da Silva Sousa

ORCID: https://orcid.org/0000-0003-4290-0472

Universidade Federal de Campina Grande, Brasil

E-mail: ssengflorest@gmail.com

Antônio Adriano da Costa

ORCID: https://orcid.org/0000-0001-6847-5959

Universidade Federal de Campina Grande, Brasil

E-mail: anthony_kettyn@hotmail.com

Gerlanny Vieira de Morais

ORCID: https://orcid.org/0000-0002-2079-6275

Universidade Federal de Campina Grande, Brasil

E-mail: gerlanny.vieira@estudante.ufcg.edu.br

\begin{abstract}
Resumo
A sociedade mais engajada e preocupada com as questões ambientais passou a discutir, cobrar e incentivar medidas que viessem a reduzir os impactos ambientais nos ecossistemas levando a criação das Unidades de Conservação (UC's) com o propósito de proteger e conservar as áreas que estivessem submetidas a processos de degradação e fossem representativas dos ecossistemas e biomas. Diante disso, o objetivo foi realizar uma análise descritiva da importância e eficácia do Plano de Manejo para Zonas de Amortecimento (ZA) de Unidades de Conservação (UC) através de pesquisas na legislação e documentos técnicos que abordem esta temática. A zona de amortecimento ou zona tampão, abrange o entorno de uma unidade de conservação onde as atividades humanas estão sujeitas a normas e restrições específicas com o propósito de minimizar os impactos negativos sobre a UC. A zona de amortecimento embora não pertença à UC, prima pela proteção da mata ciliar; preservação da paisagem; promoção da educação ambiental e à melhoria de vida da população do entorno; controle da urbanização; e planejamento e consolidação de usos adequados ao plano de manejo das UC. O estabelecimento das zonas de amortecimento deverá sempre respeitar as necessidades de cada unidade de conservação e das comunidades do entorno. Assim, são necessárias políticas públicas que promovam efetivamente os planos de manejo nas UC's com a participação direta da comunidade das ZA's. As UC's com plano de manejo apresentam reflexos positivos nas ZA. No entanto, ainda são escassas as informações concretas voltadas a eficiência de planos de manejo nas UC e ZA.

Palavras-chave: Sistema Nacional de Unidades de Conservação; Recursos florestais; Preservação ambiental; Meio ambiente.
\end{abstract}




\begin{abstract}
The most engaged and concerned society with environmental issues started to discuss, demand, and encourage measures that would reduce the environmental impacts on ecosystems leading to the creation of Conservation Units (UC's) to protect and conserve the areas that were submitted degradation processes and were representative of ecosystems and biomes. Therefore, the objective was to carry out a descriptive analysis of the importance and effectiveness of the Management Plan for Buffer Zones of Conservation Units through research in legislation and technical documents that address this issue. The buffer zone covers the surroundings of a conservation unit where human activities are subject to specific rules and restrictions to minimize negative impacts on the conserved area. The buffer zone, although it does not belong to the Conservation Units, excels in protecting the riparian forest; landscape preservation; promoting environmental education and improving the lives of the surrounding population; urbanization control; and planning and consolidation of appropriate uses for the management plan the conservation units. The establishment of buffer zones must always respect the needs of each conservation unit and surrounding communities. Thus, public policies are needed that effectively promote management plans in the Conservation Units with the direct participation of the Buffer Zones community. The Conservation Units with a management plan have positive effects on the Buffer Zones. However, concrete information regarding the efficiency of management plans in the Conservation Units and Buffer Zones is still scarce.
\end{abstract}

Keywords: National System of Conservation Units; Forest resources; Environmental preservation; Environment.

\title{
Resumen
}

La sociedad más comprometida y preocupada con los temas ambientales comenzó discutir, exigir y fomentar medidas que redujeran los impactos ambientales en los ecosistemas dando lugar a la creación de Unidades de Conservación, con el propósito de proteger y conservar las áreas que fueron sometidas a procesos de degradación o eran representativos de ecosistemas y biomas. Así, el objetivo fue realizar un análisis descriptivo de la importancia y efectividad del Plan de Manejo de Zonas de Amortiguamiento (ZA) de Unidades de Conservación a través de la investigación en legislación y documentos técnicos que aborden este tema. La ZA cubre los alrededores da unidad de conservación donde las actividades humanas están sujetas a reglas y restricciones específicas puntería minimizar los impactos negativos en la area conservada. Aunque la ZA no pertenece a la unidade de conservación, contribuir en la protección del bosque de ciliar; preservación del paisaje; promover la educación ambiental y mejorar la vida de la población circundante; control de urbanización; y planificación y consolidación de usos apropiados para el plan de manejo de unidade de conservación. El establecimiento de ZA debe respetar siempre las necesidades de cada unidad de conservación y las comunidades circundantes. Así, se necesitan políticas públicas que promuevan de manera efectiva los planes de manejo en las unidade de conservación con participación directa de la comunidad de la ZA. Las unidade de conservación con un plan de manejo tienen efectos positivos en la ZA. Sin embargo, la información concreta sobre la eficiencia de los planes de manejo en las unidade de conservación y ZA es aún escasa.

Palabras clave: Sistema Nacional de Unidades de Conservación; Recursos forestales; Preservación ambiental; Medio ambiente.

\section{Introdução}

A necessidade e o interesse da humanidade por tecnologias fizeram com que uma ampla quantidade de instrumentos fosse criada para facilitar cada vez mais a vida em sociedade. Nos dois últimos séculos isso tem sido intensificado, criando-se um ciclo sem fim de inovações, sempre surgindo novas necessidades e interesses, culminando na contemporaneidade com o consumismo. Como externalidades, aumentou-se drasticamente a exploração dos recursos naturais, muitas vezes atingindo o esgotamento dessas fontes, levando a degradação ambiental, danos a fauna e a flora, extinção de espécies, poluição, entre outros fatores (Gracia Neto, 2010). Por esses motivos, a sociedade mais engajada em questões ambientais começou a pensar em medidas que viessem a reduzir esses impactos, como manter bancos de germoplasma, exemplares naturais da fauna e flora, além de ambientes em seu estado mais representativo, levando a criação das Unidades de Conservação (UC's) com o propósito de proteger e conservar as áreas que estivessem submetidas a processos de degradação e fossem representativas dos ecossistemas e biomas. Por essa razão, o estabelecimento de áreas protegidas têm sido uma ótima estratégia de conservação mundial (Budhathoki, 2004).

As Unidades de Conservação são consideradas um dos principais dispositivos de proteção ambiental, que constituem a agenda do poder público e da sociedade civil no Brasil, compondo ferramenta de atuação direta sobre a gestão e planejamento do território (Beiroz, 2015). As UC's contribuem no cumprimento do conteúdo expresso no artigo 225 da Constituição Federal do Brasil, em que está descrito, em essência, para que todas as gerações, presentes e futuras, possuam o 
direito ao meio ambiente ecologicamente equilibrado na situação de bem uso comum, impondo-se ao poder público e a coletividade o dever de defendê-lo e preservá-lo (BRASIL, 1988). Assim, a responsabilidade abrange tanto o poder público nas suas diversas esferas, como também à sociedade em geral.

Como instrumento de regulamentação do art. 225, o Sistema Nacional de Unidades de Conservação (SNUC) criado pela Lei nº 9.985/2000 é conhecida como uma das principais atuantes para criação e gestão de áreas protegidas no país (Brasil, 2000). O SNUC tem por objetivo promover o desenvolvimento sustentável a partir dos recursos naturais, valorizar a diversidade biológica, contribuir para a preservação e restauração de habitats naturais, entre outras práticas que sirvam de amparo para a defesa do meio ambiente (Art. $4^{\circ}$ da Lei n ${ }^{\circ}$ 9.985/2000).

O SNUC é constituído por duas categorias de Unidades de Conservação, as Unidades de Conservação de Uso Sustentável e Unidade de Proteção Integral (Santana et al., 2020). O grupo de Uso Sustentável é composto por sete categorias, sendo: Área de Proteção Ambiental (APA), Área de Relevante Interesse Ecológico (ARIE), Floresta Nacional (FLONA), Reserva Extrativista (RESEX), Reserva de Fauna (REFAU), Reserva de Desenvolvimento Sustentável (RDS), Reserva Particular do Patrimônio Natural (RPPN). Enquanto o grupo de Proteção Integral é composta por cinco unidades: Estação Ecológica (ESEC), Reserva Biológica (REBIO), Parque Nacional (PARNA), Monumento Natural (MN) e Refúgio da Vida Silvestre (REVIS) (Brasil, 2000).

Dentro deste arcabouço de categorias de UC's, a depender de suas finalidades, em geral todas as possíveis áreas de proteção contam com Zona de Amortecimento (ZA) - exceto a APA e RPPN. As ZA's são caracterizadas como as áreas no entorno das UC's em que as atividades humanas podem sofrer restrições com o intuito de reduzir os impactos negativos e aumentar a conservação da biodiversidade, uma vez que a ZA tem o potencial de mitigar possíveis conflitos entre comunidades (Hjert, 2006). Pois, segundo Beiroz (2015), as maiores ameaças às unidades de conservação são advindas das atividades antrópicas presentes no entorno, por isso é importante a criação, gestão e planejamento das ZA's. Vale ressaltar que as ZA's geralmente são manejadas com o objetivo mútuo de conservação e desenvolvimento (Lynagh e Urich, 2002).

Diante disso, o objetivo do trabalho foi realizar uma análise descritiva da importância e eficácia do Plano de Manejo para Zonas de Amortecimento das Unidades de Conservação.

\section{Metodologia}

Para discussão deste estudo, buscou-se subsídio na legislação brasileira e em documentos técnicos científicos além de recorrer as plataformas de pesquisa SciELO e Google Acadêmico com uso das seguintes palavras-chaves: Unidades de Conservação; Zonas de Amortecimento; Plano de Manejo; Sustentabilidade; Impactos causados a comunidade; Importância do plano de manejo; Planejamento ambiental; Diversidade nas zonas de amortecimento e Diagnóstico da ZA.

A pesquisa científica apresenta uma grande multiplicidade e flexibilidade quanto o ponto de vista metodológico (Batista e Kumada, 2021). Dessa forma, com base nos pressupostos metodológicos e em concordância com Gil (2002), a forma mais comum de realizar um estudo é baseado no levantamento bibliográfico. A metodologia fundamentada na pesquisa exploratória permite que o pesquisador obtenha discussões sobre temas ainda poucos conhecidos/explorados, utilizando-se da união de diferentes metodologias para conclusão final do trabalho (Martelli et al., 2020).

Assim, para melhor compreensão do estudo o artigo foi dividido em três partes: introdução abordando definições e importância do estudo, em seguida uma discussão sobre os planos de manejos nas zonas de amortecimento, visando sua melhor aplicação e por fim, o conhecimento sobre as zonas de amortecimento e seu impacto na comunidade e seu entorno. 


\section{Resultados e Discussão}

\subsection{Plano de Manejo}

Conforme a Lei 9.985/2000 para melhor gestão das Unidades de Conservação é recomendado um Plano de Manejo, este é definido como:

Documento técnico que apresenta embasamento nos objetivos gerais das UC's, que deve ser estabelecido o zoneamento e as normas que devem administrar a utilização da área e os seus recursos, por meio de um manejo adequado, incluindo a inserção das estruturas necessárias para gestão (Brasil, 2000).

O SNUC determina no artigo 27, parágrafo primeiro da Lei 9.985/2000 que o Plano de Manejo deve envolver a área da unidade de conservação, sua zona de amortecimento e os corredores ecológicos abarcando medidas a fim de promover a sua integração a vida econômica e social das comunidades vizinhas (Gracia Neto, 2010). Assim, as ZA's não possuem plano de manejo estabelecido por lei, mas o plano de manejo da unidade de conservação, excetuando Áreas de Proteção Ambiental e Reserva Particular do Patrimônio Natural, devem incluir a atuação também nas zonas de amortecimento e, corredores ecológicos quando convenientes.

Segundo Vasques (2008), antes da definição de plano de manejo através do SNUC, o conceito era dado pelo Regulamento de Parques Nacionais Brasileiros aprovado pelo Decreto 84.017/1979. Era definido em seu artigo 6 como “um projeto dinâmico, que utilizando técnicas de planejamento ecológico, determina o zoneamento de um parque nacional, caracterizando cada uma das suas zonas e propondo seu desenvolvimento físico, de acordo com suas finalidades". Em consoante com o mesmo autor, o plano de manejo deve compreender todas as normas que regulamentam a UC, pois mesmo com a finalidade de prevenção, possui também caráter normativo.

Conforme a Lei 9.985 publicada em 2000 há um conjunto de objetivos específicos que cada UC deve seguir, assim como as diretrizes estabelecidas. Logo, os objetivos gerais atendem as definições de cada unidade de conservação, como os dispostos no art. $4^{\circ}$ e as diretrizes no art. $5^{\circ}$. Já os objetivos específicos, são estabelecidos em concordância com o zoneamento e as normas que irão regular a unidade de conservação (Vasques, 2008). Do mesmo modo, os objetivos que estão dispostos na lei, fazem com que as unidades de conservação estejam cada vez mais protegidas, onde a correta aplicação proporciona um ambiente estável e preservado, garantindo sua conservação e que só entrará em perigo, caso ocorra uma ruptura na unidade de conservação.

É importante a elaboração de um plano de manejo, pois muitas características da área são observadas e analisadas, e assim é montado um diagnóstico, propondo medidas de desenvolvimento e conservação conforme a finalidade da unidade de conservação e sua interação com o entorno/comunidade. Além do mais, no plano de manejo também são definidas as áreas que poderão ser exploradas, as atividades que poderão ser executadas de maneira que não degrade ou venha a poluir o meio ambiente, levando em consideração quais são as fragilidades, ameaças e oportunidades da unidade de conservação. Por esses motivos é indispensável que os gestores, cientistas, empresários, comunidade local e outros interessados trabalhem em conjunto a fim de obter resultados positivos. A interdisciplinaridade é um marco importante para desenvolvimento do plano de manejo e cumprimento dos objetivos da UC.

De acordo com o artigo 27, parágrafo $3^{\circ}$ da Lei 9.985/2000, o plano de manejo deve ser elaborado com até 5 anos após a data de criação da UC. Contudo, esse instrumento já havia sido proposto no art. 43 , parágrafo $1^{\circ}$ do Decreto 84.017/1979, no Regulamento Nacional de Parques Brasileiros. Desta maneira, o que sonda ainda é a crítica acerca do custeamento na execução do plano de manejo, onde existe uma falta de recursos suficientes pelos órgãos responsáveis para tal elaboração, motivo tal que inexista incentivos à criação e gestão de UC's. Segundo Santana et al. (2020), maior parte dos problemas enfrentados nas unidades de conservação são agravados pela falta de planos de manejo e conselho gestor. 
Portanto, mesmo com os desafios para elaboração do plano de manejo para as UC's, este deve ser levado em consideração, pois possibilita uma melhor gestão dos recursos ambientais. O que provoca falta de estímulo para preparação do plano de manejo é o alto custo, mesmo sendo exigido no prazo de cinco anos a partir da data de criação da UC. O plano de manejo quando bem elaborado oferece instrumentos de grande valia para gestão da UC e ZA, por isso é tão importante a elaboração, porque o plano de manejo vai além de um documento técnico, sendo também uma ferramenta de gestão.

\subsection{Zona de Amortecimento}

A zona de amortecimento ou zona tampão, como também é conhecida na literatura, é definida de acordo com o artigo $2^{\circ}$, inciso XVIII da lei 9.985/2000, e abrange o entorno de uma unidade de conservação, onde as atividades humanas estão sujeitas a normas e restrições específicas, com o propósito de minimizar os impactos negativos sobre a unidade (BRASIL, 2000). Logo, a zona de amortecimento assegura que as atividades desenvolvidas na área respeitem e sejam compatíveis com a unidade de conservação. Assim, ao analisar a legislação brasileira, observa-se que no Decreto nº 84.017/1979 ainda não estava estabelecido a definição de zona de amortecimento, nota-se que apenas existia um esboço, onde usava-se o termo de "zona de uso especial" preconizando que a criação de áreas necessárias à administração, manutenção e serviços do Parque Nacional, eram válidas, uma vez que a presença destas não conflitassem com as áreas de caráter natural e que deveriam estar localizadas sempre que possível nas periferias, com o objetivo de minimizar os impactos no Parque Nacional.

A zona de amortecimento oportuniza proteção as unidades de conservação, e que tão importante quanto a criação da UC é a implantação da zona de amortecimento, pois minimiza os efeitos negativos no interior da UC (PMSP, 2012). Entretanto, de acordo com Costa et al. (2009), não são estabelecidas normas prévias que esclareçam quais avaliações devem ser feitas, além dos parâmetros e medidas que devem ser analisados e levados em consideração na hora de definir uma zona de amortecimento. Por este motivo, deve-se ter muita cautela ao analisar essas áreas, principalmente as urbanas, devido a pluralidade e complexidade das áreas e do poder público.

Conforme o Roteiro Metodológico (RM) do IBAMA (2002) e Costa et al. (2009), deve-se observar alguns preceitos para definição da zona de amortecimento, sejam eles: a) Adjacência da área a ser protegida - onde refere-se a condição legal determinada pela resolução no 013/1990 da CONAMA e que deve ser obedecida, uma vez que faz parte dos objetivos propostos para zona de amortecimento, visando a proteção do interior da UC, evitando os impactos externos, tais como: ruídos, poluição, caça predatória, incêndios, desmatamento, entre outros; b) Avaliação do uso/ocupação do solo na área de entorno, sendo adotada medidas que minimizem o impacto das atividades, podendo ser: práticas sustentáveis na produção de agricultura e pecuária, utilizando da implantação de sistemas agroflorestais, regulação de suporte animal, conservação da mata ciliar, evitar uso do fogo como prática de limpeza de área, investir na construção de aceiros entre as propriedades particulares e a unidade de conservação, etc.; e, c) Adensamento da ocupação populacional - é descrito como um dos principais critérios a ser levado em consideração, uma vez que áreas muito adensadas devem se manter longe das zonas de amortecimento, para evitar impactos advindos principalmente das ações antrópicas.

Nesse caso, em concordância com Ribeiro et al. (2010), foi uma conquista as normativas que exigem a implantação das zonas de amortecimento para toda unidade de conservação, isto é, a adjacência da UC também fica passível a restrição, de maneira a diminuir os impactos derivados do aumento das pressões sobre os espaços protegidos. Deste modo, o art. $5^{\circ}$, parágrafo $1^{\circ}$ da Lei 9.985/2000, descreve que compete ao órgão responsável pela administração da unidade estabelecer normas específicas regulamentando a ocupação e o uso dos recursos da zona de amortecimento e dos corredores ecológicos de uma unidade de conservação. No mesmo sentido, dispõe também dos limites da zona de amortecimento e dos corredores ecológicos na cerimônia de sua criação ou em momento posterior, em consoante com o plano de manejo. 
Ribeiro et al. (2010), afirmam que a zona de amortecimento não pertence a unidade de conservação, entretanto em função da lei, a zona fica sujeita a um zoneamento obrigatório, onde regula e autoriza certas atividades econômicas. Deste modo, em harmonia com o art. 49, parágrafo único da Lei 9.985/2000, estabelece que após definir formalmente a zona de amortecimento, esta não poderá ser transformada em zona urbana. Segundo Vio (2001, p. 349) apud Ribeiro et al. (2010), as zonas de amortecimento devem assessorar nos seguintes itens:

- Proteção da mata ciliar, para conservar a qualidade e quantidade da água;

- Preservação da paisagem, a fim de contribuir no turismo ecológico, com participação das empresas privadas;

- Aumento das oportunidades de lazer e recreação para a população do entorno das unidades de conservação;

- Promoção da educação ambiental, para fortalecer atitudes mais ligadas a conservação ambiental e à melhoria de vida;

- Controle da urbanização incessante e desenfreada;

- Planejamento e consolidação de usos adequados e de atividades complementares que respondam positivamente as propostas do plano de manejo e das UC (Vio, 2001, p. 349) apud (Ribeiro et al., 2010).

Ainda assim, de acordo com Vio (2001, p. 349) apud Ribeiro et al. (2010), são indicados os problemas que designam a importância da implantação das zonas de amortecimento, sendo eles:

- Controle do efeito de borda, proporcionado através das ações antrópicas no ambiente natural de proteção integral, podendo ser justificado devido a decorrente pressão que as zonas rurais sofrem pela expansão da malha urbana, em virtude da instalação de indústrias, estabelecimento de loteamentos privados, programas habitacionais públicos, etc. As bordas da unidade de conservação são vulneráveis a atividades que causam degradação, visto que atuam no interior das unidades, causando "efeitos de borda" (Machado et al., 2017);

- Mitigação dos impactos derivados de práticas não sustentáveis, principalmente o uso de agrotóxicos de forma descuidada e imprecisa, e o manejo do fogo sem permissão, controle e conhecimento;

- Interesse no aumento do espaço físico das UC's, em decorrência da diminuição de habitat, pois este motivo já ocasionou extinção de muitas espécies, tanto da fauna quanto da flora (Vio, 2001, p. 349) apud (Ribeiro et al., 2010).

O estabelecimento das zonas de amortecimento deverá sempre respeitar as necessidades de cada unidade de conservação, além das pessoas envolvidas nas comunidades do entorno, que pertencem a área protegida (Ribeiro et al., 2010). Mesmo que a zona de amortecimento deva obrigatoriamente cumprir a sua função de proteger os recursos do interior da UC, deve-se respeitar as áreas antes de torná-la UC (Costa et al., 2007). Dessa maneira, conforme Moreira (2015), o Roteiro Metodológico de Planejamento de Parques Nacionais, Reservas Biológicas e Estações Ecológicas do IBAMA (2002) é um documento essencial para orientação e definição de uma zona de amortecimento no Brasil. De acordo com o mesmo autor os estados de Amazonas, Mato Grosso do Sul, Rio de Janeiro e Pará, já lançaram seus roteiros metodológicos e apresentam critérios similares ao roteiro do IBAMA (2002).

Assim, avaliando alguns estudos que abordaram as zonas de amortecimento e o nível de conservação nessas áreas, temos que os resultados são positivos, pois contribuem com a diversidade das espécies, riqueza florística, proteção dos aquíferos através da presença da mata ciliar, entre outros benefícios voltados a preservação e diversidade da área.

Como visto no trabalho de Pereira et al. (2018), comparando a estrutura da vegetação arbórea da UC com a mata ciliar da zona de amortecimento, constatou que é notável a importância da zona de amortecimento para a conservação, pois influencia diretamente na composição e diversidade das espécies do interior da UC.

Já Steyer et al. (2020), ao estudarem iniciativas de produção agroecológica na zona de amortecimento da Flona Ipanema, Iperó - SP, verificaram que este tipo de processo contribui significativamente com a conservação ambiental, uma vez que a aproximação entre a Flona e o Assentamento Ipanema, pode promover múltiplas ações, como: geração de empregos por meio do turismo em bases sustentáveis, implantação de programas educacionais para a comunidade, incentivo da participação da comunidade na gestão da Flona, etc. 
De acordo com Trindade e Rodrigues (2019), os resultados apresentados na pesquisa levantada mostraram os benefícios e a importância da criação das UC e ZA, visto que a implantação destas corroborou com o ordenamento do uso do solo e a proteção dos recursos hídricos e florestais. No entanto, os autores notaram que na ZA houve maior perda de floresta nativa, quando comparado com a UC. Nesse sentido, Alves e Brito (2020), ao avaliarem a Estação Ecológica do Seridó e sua ZA com relação a comunidade, observaram que boa parte dos moradores da comunidade não reconhecem que fazem parte da ZA, os autores afirmam que o propósito da área pela população é desconhecido.

Conforme Sousa e Santos (2020), ao analisarem a dinâmica da mudança do uso de cobertura da terra em uma paisagem de Caatinga protegida do Parque Estadual Mata da Pimenteira e sua ZA, observaram que antes da criação e após a criação da UC na área, o índice de uso antrópico diminuiu gradualmente no decorrer dos anos após a implantação, apresentando em 2008, antes da criação da UC uma taxa de 59,69\% de uso antrópico na área, após a criação da UC suas taxas foram oscilando, até que em 2018 obteve uma taxa de 33,07\%, demostrando com esses valores a importância da ZA no entorno das UC's.

Contraponto a esses dados, Marques et al. (2019), ao realizarem estudo no Parque Estadual Mata do Pau Ferro em Areia - PB, mencionaram que a falta do plano de manejo tem intensificado o uso da zona de amortecimento, com divergentes áreas de conflitos e monopólios territoriais. Já Lamichhane et al. (2019), apontaram em seu estudo a necessidade de aumentar o investimento nas zonas de amortecimento, visando minimizar os impactos negativos na biodiversidade do ambiente.

De acordo com Neiva (2020), as zonas de amortecimento possuem uma alta biodiversidade quando comparada com outros tipos de áreas que sofrem pressões antrópicas, mas a serventia da área ainda é pouco conhecida por seus moradores, quanto a seus benefícios e potenciais conflitos.

Logo, segundo Vio (2001, p. 349) apud Ribeiro et al. (2010), é importante salientar que as zonas de amortecimento têm caráter dinâmico e que a criação delas não é para limitar os avanços econômicos da região, mas sim determinar, estabelecer, guiar e promover a interação entre todas as atividades compatíveis, incentivando a interação entre os municípios com a unidade de conservação, para que possa existir uma base sólida para auxiliar tanto no desenvolvimento social quanto no econômico, de forma que seja respeitada as características e potencialidades da região.

\section{Considerações Finais}

Portanto, é possível perceber com esse trabalho que as Zonas de Amortecimento são de extrema importância para as UC's, uma vez que a presença destas contribui significativamente com a conservação e preservação das unidades. É necessário que haja existência de políticas públicas que promovam a elaboração e execução efetiva dos planos de manejo nas UC's com a participação direta da comunidade das ZA's.

Ressalta-se ainda, que as UC's que possuem plano de manejo, melhor administram as atividades desenvolvidas e refletem positivamente nas ZA, o inverso ocorre quando não há de planos de manejo, como: má gestão dos recursos ambientais e institucionais, incentiva conflitos dentro da própria comunidade e entre a comunidade e a unidade de conservação, proporciona desordem entre os objetivos da unidade de conservação e as atividades desenvolvidas pela população do entorno, entre outras problemáticas. Há ainda uma ausência de informações mais concretas ou até mesmo estudos voltados a eficiência de planos de manejo nas UC e ZA.

\section{Referências}

Alves, J. B. \& Brito, S. A. A. (2021). Estação Ecológica do Seridó e sua Zona de Amortecimento: relação com a comunidade. Boletim de Geografia, 38(3), 76-93. https://doi.org/10.4025/bolgeogr.v38i3.46799.

Beiroz, H. (2015). Zonas de amortecimento de Unidades de Conservação em ambientes urbanos sob a ótica territorial: reflexões, demandas e desafios. Desenvolvimento. Meio Ambiente, 35, 275-286. http://dx.doi.org/10.5380/dma.v35i0.38253 
Brasil. (1979). Decreto $\mathrm{n}^{\mathrm{o}}$ 84.017, de 21 de setembro de 1979. Aprova o Regulamento dos Parques Nacionais Brasileiros. http://www.planalto.gov.br/ccivil_03/Atos/decretos/1979/D84017.html

Brasil. (1988). Constituição da República Federativa do Brasil. Brasília, DF: Senado Federal: Centro Gráfico. http://www.planalto.gov.br/ccivil_03/constituicao/ConstituicaoCompilado.htm

Brasil. (2000). Lei 9.985, de 18 de julho de 2000. Institui o Sistema Nacional de Unidades de Conservação da Natureza e dá outras providências. http://www.planalto.gov.br/ccivil_03/leis/19985.htm

Batista, L. S. \& Kumada, K. M. O. Análise metodológica sobre as diferentes configurações da pesquisa bibliográfica. Revista Brasileira de iniciação científica, 8, 1-17, 2021. https://periodicoscientificos.itp.ifsp.edu.br/index.php/rbic/article/view/113/235

Budhathoki, P. (2004). Linking communities with conservation in developing countries: Buffer zone management initiatives in Nepal. Oryx, 38(3), p. 334-341. https://doi.org/10.1017/S0030605304000584.

Costa, N. M. C., Costa, V. C. \& Santos, J. P. C. S. (2009). Definição e caracterização de áreas de fragilidade ambiental, com base em análise multicritério, em zona de amortecimento de unidades de conservação. Anais $-12^{\circ}$ Encuentro de Geógrafos de América Latina - EGAL - Caminando en una América Latina en transformación, Montevideo - Uruguai. http://observatoriogeograficoamericalatina.org.mx/egal12/Nuevastecnologias/Sig/08.pdf

Costa, N. M. C., Costa, V. C., Valim, C. B., Souza, A. C. C. C., Sales, A. C. G. (2007). Significado e importância da zona de amortecimento de unidades de conservação urbanas: o exemplo do entorno das áreas legalmente protegidas da cidade do Rio de Janeiro. Geo UERJ, 1(17). https://www.epublicacoes.uerj.br/index.php/geouerj/article/view/1298

Gracia Neto, T. (2010). Critérios para definição de perímetro e atividades para a Zona de Amortecimento da FLONA de Irati, PR. (Dissertação) - Mestrado em Ciências Florestais - Universidade Estadual do Centro-Oeste - UNICENTRO, 2010. https://www2.unicentro.br/ppgf/2014/11/28/criterios-para-definicaode-perimetro-e-atividades-para-a-zona-de-amortecimento-da-flona-de-irati-pr/

Gil, A. C. (2002). Como classificar as pesquisas. Como elaborar projetos de pesquisa, 4, 44-45.

Hjert, C. J. (2006). Wildlife: Buffer zone to integrate wildlife conservation and development? Södertörns Högskola - University college. https://www.divaportal.org/smash/get/diva2:16450/FULLTEXT01.pdf.

IBAMA. (2002). Roteiro Metodológico de Planejamento - Parque Nacional, Reserva Biológica, Estação Ecológica. https://uc.socioambiental.org/sites/uc/files/2019-04/roteiroplanomanejo.pdf

Lamichhane, B. R., Persoon, G. A., Leirs, H., Poudel, S., Subedi, N., Pokheral, C. P., Bhattarai, S., Gotame, P., Mishra, R. \& Iongh, H. H. (2019). Contribution of Buffer Zone Programs to Reduce Human-Wildlife Impacts: The Case of the Chitwan National Park, Nepal. Human Ecology, 47, 95-110. https://doi.org/10.1007/s10745-019-0054-y.

Lynagh, F. M. \& Urich, P. B. (2002). A Critical Review of Buffer Zone Theory and Practice: A Philippine Case Study. Society and Natural Resources, 15, 129-145. https://doi.org/10.1080/089419202753403319.

Machado, C. C. C., Gonçalves, C. U., Albuquerque, M. B. \& Pereira, E. C. (2017). Protected areas and their multiple territorialities - a social and environmental reflection on Catimbau National Park - Brazil. Ambiente e Sociedade, 20(1), 239-260. https://www.scielo.br/scielo.php?script=sci_arttext\&pid=S1414-753X2017000100239

Marques, A. L., Costa, C. R. G. \& Moura, D. C. (2019). Parque Estadual Mata do Pau Ferro (Areia-Paraíba): Zona De Amortecimento e Espaços de Conflitos. Geoambiente On-Line, 34, 1-18. Disponivel: https://www.revistas.ufg.br/geoambiente/article/view/52282

Martelli, A., Oliveira Filho, A. J., Guilherme, C. D., Dourado, F. F. M. \& Samudio, E. M. M. (2020). Análise de Metodologias para Execução de Pesquisas Tecnológicas, 4 (2), 468-477, 2020. 10.34115/basrv4n2-006.

Moreira, V. A. (2015). Zona de amortecimento em unidades de conservação: normas, estudos de caso e recomendações. (Dissertação) - Mestrado em Gestão de Áreas Protegidas na Amazônia do Instituto Nacional de Pesquisa da Amazônia - INPA. Manaus - AM. https://bdtd.inpa.gov.br/bitstream/tede/2330/5/dissertao_vincius_final_20160107171535192.pdf

Neiva, C. H. M. B. (2020). Eventos de educação ambiental em uma zona de amortecimento. Brazilian Journal of Animal and Environmental Research, 3(3), 2020-2028. https://www.brazilianjournals.com/index.php/BJAER/article/view/15179/12529

Pereira, K. M. G., Cordeiro, N. G., Santana, L. D., Plazas, I. V. C., Matos, L. M. A. \& Cabacinha, C. D. (2018). Relações estruturais e de diversidade de uma floresta ripária em unidade de conservação e sua zona de amortecimento. Revista Verde de Agroecologia e Desenvolvimento Sustentável, 13(4), 508-520. https://www.gvaa.com.br/revista/index.php/RVADS/article/view/5822.

PMSP - Prefeitura do Município de São Paulo. (2012). Plano de Manejo do Parque Natural do Munícipio da Cratera de Colônia. https://www.prefeitura.sp.gov.br/cidade/secretarias/upload/meio_ambiente/arquivos/plano_de_manejo_pnm_crateradecolonia_2012.pdf.

Ribeiro, M. F., Freitas, M. A. V. \& Costa, V. C. (2010). O desafio da gestão ambiental de zonas de amortecimento de unidades de conservação. Anais. VI Seminário Latino-Americano de Geografia Física. Coimbra. http://arquivos.proderj.rj.gov.br/inea_imagens/downloads/pesquisas/Ribeiro_etal_2010.pdf

Santana, V. V., Santos, P. R. \& Barbosa, M. V. (2020). Contribuições do Plano de Manejo e do Conselho Gestor em Unidades de Conservação. Meio Ambiente, 2(2), 18-29. https://www.meioambientebrasil.com.br/index.php/MABRA/article/view/39/37.

Steyer, F. S., Costa Junior, J. M., Bergamasco, S. M. P. P. \& Souza-Esquerdo, V. F. (2020). As iniciativas de transição agroecológica na zona de amortecimento da Flona Ipanema, Iperó/SP. Anais do XI Congresso Brasileiro de Agroecologia, São Cristóvão, Sergipe, 15(2), http://cadernos.abaagroecologia.org.br/index.php/cadernos/article/view/4516. 
Research, Society and Development, v. 10, n. 14, e133101421775, 2021

(CC BY 4.0) | ISSN 2525-3409 | DOI: http://dx.doi.org/10.33448/rsd-v10i14.21775

Sousa, J. S. \& Santos, E. M. (2020). Dinâmica da mudança do uso e cobertura da terra em uma paisagem da Caatinga protegida e sua zona de amortecimento. Ibero Americana de Ciências Ambientais, 11(7), 219-234. http://doi.org/10.6008/CBPC2179-6858.2020.007.0020

Trindade, S. P. \& Rodrigues, R. A. (2019). Mudanças de uso do solo na Zona de Amortecimento do Parque Estadual Serra de Caldas: Influência pedológica na preservação da vegetação. Caminhos de geografia, 20(72), 01-14. https://doi.org/10.14393/RCG207241128.

Vasques, P. H. R. P. (2008). A aplicação do plano de manejo, zona de amortecimento e corredores ecológicos na proteção da biodiversidade. Relatório do NIMA - Núcleo Interdisciplinar do Meio Ambiente. Rio de Janeiro, 2008. http://www.pucrio.br/pibic/relatorio_resumo2008/ relatorios/ccs/dir/relatorio_pedro_vasques.pdf.

Vio, A. P. A. (2001). Zona de amortecimento e corredores ecológicos. In: Benjamin, A. H. Direito ambiental das áreas protegidas - o regime jurídico das Unidades de Conservação. 